https://helda.helsinki.fi

\title{
Exploring lot-to-lot variation in spoilage bacterial communities on commercial modified atmosphere packaged beef
}

\section{Säde, Elina Johanna}

2017-04

Säde , E J , Penttinen , K , Björkroth , K J \& Hultman , J J 2017 , ' Exploring lot-to-lot variation in spoilage bacterial communities on commercial modified atmosphere packaged pÿbeef ' , Food Microbiology , vol. 62 , pp. 147152 . https://doi.org/10.1016/j.fm.2016.10.004

http://hdl.handle.net/10138/308483

https://doi.org/10.1016/j.fm.2016.10.004

cc_by_nc_nd

acceptedVersion

Downloaded from Helda, University of Helsinki institutional repository.

This is an electronic reprint of the original article.

This reprint may differ from the original in pagination and typographic detail.

Please cite the original version. 


\section{Exploring lot-to-lot variation in spoilage bacterial communities on commercial}

modified atmosphere packaged beef

Elina Säde*, Katri Penttinen, Johanna Björkroth and Jenni Hultman

Department of Food Hygiene and Environmental Health, Faculty of Veterinary Medicine, University of Helsinki, Finland

* Address for correspondence to: Elina Säde, Department of Food Hygiene and Environmental Health, University of Helsinki, P.O. Box 66, 00014 Helsinki University, Finland. Tel +358 91915 7118; Fax +358919157101; email: elina.sade@helsinki.fi

Running title: Bacterial communities on beef 


\section{Abstract}

Understanding the factors influencing meat bacterial communities is important as these communities are largely responsible for meat spoilage. The composition and structure of a bacterial community on a high- $\mathrm{O}_{2}$ modified-atmosphere packaged beef product were examined after packaging, on the use-by date and two days after, to determine whether the communities at each stage were similar to those in samples taken from different production lots. Furthermore, we examined whether the taxa associated with product spoilage were distributed across production lots. Results from 16S rRNA amplicon sequencing showed that while the early samples harbored distinct bacterial communities, after $8-12$ days storage at $6^{\circ} \mathrm{C}$ the communities were similar to those in samples from different lots, comprising mainly of common meat spoilage bacteria Carnobacterium spp., Brochothrix spp., Leuconostoc spp. and Lactococcus spp. Interestingly, abundant operational taxonomic units associated with product spoilage were shared between the production lots, suggesting that the bacteria enable to spoil the product were constant contaminants in the production chain. A characteristic succession pattern and the distribution of common spoilage bacteria between lots suggest that both the packaging type and the initial community structure influenced the development of the spoilage bacterial community.

Keywords: beef, spoilage, meat microbiome, modified atmosphere packaging, shelf life 


\section{Introduction}

Bacterial communities are largely responsible for meat spoilage and therefore characterization of those communities is of importance. The species composition and the abundance of each taxa, termed community structure, may have a major impact on the spoilage process mainly due to varying growth rates and metabolic capabilities of the different taxa. Thus, shifts in community structure may lead to a different type of spoilage defect or affect the shelf life of meat (Jääskeläinen, et al. 2016). However, linking a spoilage defect to a community structure profile is challenging since bacterial communities are complex and highly dynamic. Therefore, even small variations in storage temperature, packaging atmosphere, muscle $\mathrm{pH}$ or other physicochemical characteristics may influence the spoilage process by shaping the structure and metabolic activities of the bacterial community.

During the past five years, microbial communities, and particularly the changes in community structure that precedes meat spoilage, have been examined through cultureindependent, high-throughput sequencing techniques (Chaillou, et al. 2015, De Filippis, et al. 2013, Ercolini, et al. 2011, Ercolini 2013, Jääskeläinen, et al. 2016, Kiermeier, et al. 2013, Nieminen, et al. 2012, Stoops, et al. 2015, Zhao, et al. 2015). These approaches have enabled the simultaneous collection of thousands of 16S rRNA gene amplicon sequences, and allowed detailed characterization of bacterial communities in various meats. It is well established, that packaging meat under a modified atmosphere (MA) initiates an ecological succession of psychrotrophic bacteria that tolerate the altered atmosphere within the package (for a review, see Pothakos, et al. 2015). This research has deepened our understanding of how meat bacterial communities develop 
during extended chilled storage, and shown that Brochothrix thermosphacta, and psychrotrophic species of lactic acid bacteria (LAB) and Enterobacteriacae are usually the abundant bacteria at the time of spoilage.

The underlying mechanisms for bacterial succession associated with the spoilage of packaged meats are not completely understood, but it is well established that the composition of the modified atmosphere (MA) is a key driver shaping the community structure and function, and hence, the spoilage process (Ercolini, et al. 2006, Ercolini, et al. 2011, Jääskeläinen, et al. 2016, Nieminen, et al. 2015, Stoops, et al. 2015). Although rarely studied systematically, the structure of the initial bacterial community may be important in defining the bacterial succession pattern in the final product. In the case of commercial meat products, the processing practices and condition, as well as the potential resident microbiome of the factory environment, will influence the initial meat microbiome and may also contribute to the development of spoilage bacterial community (De Filippis, et al. 2013, Hultman, et al. 2015, Stellato, et al. 2016, Stoops, et al. 2015). At present, most studies exploring microbial community succession in packaged meat have been carried out on homogeneous meat material cut and packaged under experimental conditions. Nevertheless, more research is needed to determine whether these findings are applicable to meat products manufactured in commercial meat processing plants, where the initial meat community composition and structure may vary between different lots due to varying processing conditions and practices. Here, we sampled commercially produced high-O2 MAP beef from six production lots, and used 16S rRNA amplicon sequencing to characterize bacterial communities at three stages of the product's shelf-life: after packaging ("early"), on the 
use-by date, and two days after ("spoiled"). Specifically, we aimed to determine (i) whether the bacterial community profiles at each stage were similar to those in samples from different production lots; and (ii) whether the taxa associated with product spoilage were shared across production lots.

\section{Materials and methods}

\subsection{Product description and sample collection}

The target product consisted of boneless beef shoulder steaks ( 2 to 3 steaks per package) with a total weight of $400 \mathrm{~g}$. The steaks were prepared from shoulder cuts and packaged in a mixture of $\mathrm{O}_{2}(70 \%)$ and $\mathrm{CO}_{2}(30 \%)$ during routine operation in a beef processing plant. Prior to processing, the shoulder cuts used as raw material were stored in cold rooms $\left(2{ }^{\circ} \mathrm{C}\right)$ for $1-4$ days, depending on the production schedule. Since the length of the buffer-storage stage was a process variable that could influence the bacterial community, we included samples from lots processed from fresh shoulder cuts (stored $<2 \mathrm{~d}$ ) and lots that were processed from batches stored for 3-4 days prior to processing. During a 3-weeks period, we collected 3 packages from 6 production lots processed on separate days to obtain a total of 18 packages. The packages were transferred and stored until sampling at $6{ }^{\circ} \mathrm{C}$, a temperature used by the processor for setting and verifying the product's commercial shelf-life.

We sampled one package from each lot at the following time points:1) within 2 days after packaging to profile the early bacterial communities ("early"); 2) at the processordefined use-by date (8-10 days after packaging); and 3) two days after the use-by date 
(10-12 days after packaging; termed "spoiled") to characterize the spoilage bacterial communities. The samples were named with a progressive letter (A to $F$ ) indicating the production lot, and the age of meat (days post-slaughter) at the time of analysis.

\subsection{Characterization of bacterial communities using 16S rRNA gene amplicon} sequencing

\subsubsection{DNA extraction and 16S rRNA V1-V3 amplicon sequencing}

For DNA extraction, $30 \mathrm{~g}$ of meat was diluted into $30 \mathrm{ml} 0.1 \%(\mathrm{w} / \mathrm{v})$ peptone-saline water and stomachered for $30 \mathrm{~s}$ at a low setting in Stomacher 400 (Seward, West Sussex, UK). The supernatants from homogenization were centrifuged in $15 \mathrm{ml}$ conical tubes at 800 rcf for 2 min to separate the mammalian and bacterial cells. The bacterial cells were pelleted by centrifuging $10 \mathrm{ml}$ of the supernatant from the first centrifugation at $10,000 \mathrm{rcf}$ for $5 \mathrm{~min}$.

DNA was extracted with phenol-chloroform and the bead beating method (Hultman, et al. 2015), and the V1-V3 region of the 16S rRNA gene was PCR amplified with primers $8 f$ and 518r (Edwards, et al. 1989) as described previously (Hultman, et al. 2015). Briefly, Phusion polymerase (Life Technologies, Carlsbad, CA, USA) was used in 20 cycles of PCR following purification with 0.9X Ampure beads (Beckman Coulter, Pasadena, CA, USA). The sample specific barcodes ( $8 \mathrm{bp})$ and sequencing adapters were added to the amplified PCR fragments in a second PCR. Three replicate PCR reactions were done per sample and the products were pooled prior to a second round of purification with Ampure beads.16S rRNA amplicons were sequenced at the Institute of Biotechnology, University of Helsinki using the Roche 454 Titanium FLX protocol. A 
total of 64,228 sequence reads were recovered. The raw $16 \mathrm{~S}$ rRNA gene sequences have been deposited in the Sequence Read Archive (SRA) of NCBI (submission ID SUB1368945).

\subsubsection{Data processing and statistical analysis}

Sequences were analyzed with QIIME (Caporaso, et al. 2010a), and a flowchart of the processing and analysis steps is presented in supplementary Fig. S1. First, the sequence reads were quality filtered and reads with a length of less than $200 \mathrm{bp}$, containing ambiguous bases, with a quality score below q25 or mismatches in the primer sequence were discarded, and the remaining reads were assigned to samples based on the sample specific barcode.

OTUs (Operational Taxonomic Units) were picked using the cd-hit algorithm ( $\mathrm{Li}$ and Godzik. 2006) with 97\% nucleotide similarity level, and the representative sequence read from each OTU was assigned to taxonomy with BLAST (Altschul, et al. 1990) against the GreenGenes database (Version 13.8.2014, (DeSantis, et al. 2006).

For sample diversity analysis, the created OTU table was rarified to the lowest number of sequence reads used in the analysis (sample $F(6), 1400$ reads). Alpha and beta diversity metrics were calculated from the rarified OTU table with QIIME and R statistical software (R Development Core Team. 2011) package vegan 1.8-2 (Oksanen, et al. 2008). For beta diversity indices, the OTU sequences were aligned with PyNast (Caporaso, et al. 2010b), and a phylogenetic tree was built from the filtered alignment with FastTree (Price, et al. 2010). Weighted UniFrac distance matrix (Lozupone and Knight. 2005), incorporating both the abundance of the OTUs as well as the 
phylogenetic relationship among the OTUs in the computation, was used for beta diversity analysis. Principal coordinate analysis (PCoA) was performed for the UniFrac distance matrix. In addition, Adonis from R-package Vegan (Oksanen, et al. 2008) was used to calculate whether the UniFrac distances are significantly associated with lot or sampling point (early and use-by date).

The genus level differences among the early and use-by date samples were compared with Welch's two-sided T-test with Storey FDR correction. Confidence interval was calculated with Welch's inverted method.

\subsection{Microbiological analysis}

A sample of $25 \mathrm{~g}$ targeting meat surfaces was taken, stomachered and decimally diluted in $0.1 \%(\mathrm{w} / \mathrm{v})$ peptone-saline water. Appropriate sample dilutions were plated and incubated as follows: i) for aerobic plate count pour-plated on Plate Count Agar (PCA, Oxoid, Basingstoke, UK) incubated at $30^{\circ} \mathrm{C}$ for 3 days; ii) for Brochothrix thermosphacta surface-plated on streptomycin-thallous acetate-actidione agar (STAA, Oxoid), incubated at $25^{\circ} \mathrm{C}$ for 2 days iii) for Enterobacteriaceae pour-plated on Violet red bile glucose (VRBG) agar (Lab M, Bury, UK), incubated at $30^{\circ} \mathrm{C}$ for 2 days; and iv) for LAB surface-plated on de Man-Rogosa-Sharpe (MRS, Oxoid, pH 6.2), incubated at $25^{\circ} \mathrm{C}$ for 4 days in an anaerobic atmosphere with $8-10 \%$ of $\mathrm{CO}_{2}$ (Anaerogen, Oxoid).

Colony counts were transformed to log values (log CFU/g). In three instances where colonies were detected below the limit of detection, we recorded the values as half the limit value (log 1.0 or $0.5 \mathrm{CFU} / \mathrm{g}$ ) of the procedure. Shapiro-Wilk test was used to test for the normality of results and a one-way ANOVA with Tukey's post hoc in SPSS (ver. 
23, SPSS, New York, USA) was used to test for significant $(P<0.05)$ differences between colony counts obtained.

\subsection{Identification of predominant $L A B$ cultured from meat}

For identification of the predominant LAB, we picked isolates from MRS plates of samples analyzed at the end of the storage period. Ribotyping-based identification was performed as described previously (Vihavainen, et al. 2008) using probes targeting the 16S and 23S rRNA genes. Briefly, HindIII -digested DNA fragments were resolved by agarose gel electrophoresis and blotted onto a nylon membrane. Southern blots were hybridized with labeled probes, and the labeled fragments were detected and visualized to reveal a ribotyping fingerprint. Ribotyping patterns were analyzed using the BioNumerics software (version 5.10; Applied Maths, Sint-Martens-Latem, Belgium). Patterns of isolates from this study were compared against patterns of 350 reference stains by cluster analysis: clusters of ribopatterns were generated based on the Dice similarity coefficient and a dendrogram was created using the unweighted pair group method with arithmetic mean (UPGMA) method. Strains assigned to the same ribotype with a reference strain were attributed to that species.

\subsection{Other product characteristics}

Headspace gas analysis was conducted as follows: prior to opening the package, an air-tight septum was attached to the package. $\mathrm{O}_{2}$ and $\mathrm{CO}_{2}$ concentrations (\%) inside the package were measured using a Checkpoint $\mathrm{O}_{2} / \mathrm{CO}_{2}$ headspace gas analyzer (PBI Dansensor, Ringstedt, Denmark) by withdrawing gas through a needle pierced through the septum. 
Sensory evaluation was conducted by a trained panel of at least four members. The panelists assessed one steak from each package scoring the odor and appearance on a four-point scale in which $4=$ good; $3=$ acceptable; $2=$ unacceptable with a clear defect; and 1 = unacceptable with a severe defect. The panelists were asked to describe the defects for samples graded "unacceptable". Fresh $(<48 \mathrm{~h})$ beef steaks of the same product type stored at $6 \stackrel{\circ}{\circ}$ were used as references.

The $\mathrm{pH}$ was determined using a pH electrode (Inolab 720, WTW, Weilheim, Germany) from the meat homogenate prepared for microbial enumeration.

\section{Results and discussion}

\subsection{Sample characteristics}

To compare bacterial communities in a high- $\mathrm{O}_{2}$ MAP beef product shortly after packaging (termed "early"), at the use-by date and two days after (collectively termed “late”), we generated 45,897 high-quality $16 \mathrm{~S}$ rRNA amplicons representing 1,174 OTUs ( $97 \%$ nucleotide identity). The colony counts determined for the main spoilage microbial groups were similar to those reported previously for high- $\mathrm{O}_{2}$ MAP beef (Jääskeläinen, et al. 2016). As expected, the colony counts in the late samples were higher $(p<0.05)$ compared to those recovered from the early samples (Table 1$)$. For most samples, the highest colony counts were obtained for $L A B$, suggesting that $L A B$ formed a major fraction of the bacterial communities at both early and later stages of the product shelf-life (Table 1). 
Regarding general product characteristics (Table S1), the headspace gas contents, muscle $\mathrm{pH}$ and sensory scores for odor and appearance were similar to values and sensory characteristics from two recent studies of high- $\mathrm{O}_{2}$ MAP beef (Jääskeläinen, et al. 2016, Stoops, et al. 2015), except for samples from lot C, where the headspace gas composition failed to comply with the product specification due to unexpectedly low $\mathrm{O}_{2}$ contents $(20-21 \%$; see Table $\mathrm{S} 1)$. Since the amount of $\mathrm{O}_{2}$ in the MA can be a critical factor for bacterial succession, we decided to report and discuss the results regarding community structure for lot $C$ samples separately from other lots.

\subsection{Quantitative comparison of bacterial community diversity across samples}

To compare the bacterial communities between the six lots and three time points (early, use-by date and spoiled), we conducted a weighted UniFrac analysis and visualized the UniFrac distances in a PCoA plot (Fig. 1). The UniFrac analysis showed a clear separation (Adonis $\mathrm{R}^{2}=32.4 \% ; \mathrm{p}<0.001 ; 49.4 \%$ when lot $\mathrm{C}$ was excluded) of the early bacterial communities (Fig. 1), suggesting that they each harbored a unique bacterial community. The late bacterial communities were more similar to each other across production lots, and the use-by date communities clustered together with the spoiled communities (Fig.1). Taken together, these results suggest that the bacterial succession followed a similar pattern in the five production lots package under a high$\mathrm{O}_{2} \mathrm{MA}$. The samples from lot $\mathrm{C}$ clustered separately from other lots, suggesting that they harbored a distinct bacterial community.

Although samples from lots $D, E$ and $F$ were prepared from older (3-4 d) raw material batches, they developed a similar spoilage bacterial community that clustered together with those of samples processed from fresh meat cuts (lots A and B). This 
suggests that the storage-age of raw material (1-4 d) was not a key factor defining the spoilage community structure in the final product. This study focused on bacterial communities on packaged meat and it is possible that the changes in the initial bacterial communities that were induced during extended chilled storage of the raw material were masked due to cross-contamination during final cutting and packaging stages (Stellato, et al. 2016), or due to the short-term storage under MA prior to analyses. Nevertheless, the influence of the initial community composition on the bacterial community dynamics in the final product has rarely been investigated, and hence, provides an interesting context for further investigations.

\subsection{Distribution of common OTUs across production lots}

To determine whether common abundant OTUs were shared across production lots, we searched the data for "core" bacteria, which we defined as an OTU that was detected in all samples of five lots (excluding lot C). Among the 20 most abundant OTUs in 15 samples (Table S2), 18 constituted the core bacteria and were assigned to taxa associated with meat spoilage including Carnobacterium spp. (10 of 18 OTUs), Brochothrix spp. (4), Lactococcus spp. (2), and Leuconostoc spp. (2). Being shared across production lots and able to prevail in the late samples suggests that these core bacteria were consistent contaminants of this product, and able to reach high numbers during refrigerated storage. It is unclear whether the core bacteria had a common source or route to the production chain, or whether they were constantly re-introduced to the product as chance contaminants from various sources (Dušková, et al. 2016, Pothakos, et al. 2015, Stellato, et al. 2016). However, a recent study in a meat processing plant showed that meat-contact surfaces served as reservoirs for 
Brochothrix spp. and spoilage LAB contamination (Hultman, et al. 2015), and suggested that refrigerated food-processing plants provide conditions which allow for the survival and persistence of meat spoilage bacteria.

\subsection{Bacterial community structure}

High- $\mathrm{O}_{2} \mathrm{MA}$ is a popular gas mixture used for the retail packing of fresh meats, but the bacteria associated with spoilage of commercially produced high- $\mathrm{O}_{2} \mathrm{MAP}$ meat have been reported in only a few cases (Nieminen, et al. 2011, Vihavainen and Björkroth. 2007). Our results show, that both early and late communities (lots A, B and D-F) in this high- $\mathrm{O}_{2}$ MAP beef product were dominated by LAB and Brochothrix spp. (Fig. 2; see also Table S3), and primarily consisted of Carnobacterium spp. (mean relative abundance $40 \pm 12 \%)$, Brochothrix spp. (32 $\pm 12 \%)$, Leuconostoc spp. (15 $\pm 8 \%)$

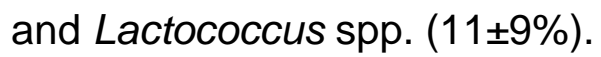

The early communities were more diverse compared to the late communities (Fig. 1; Table S3). In addition to meat-associated LAB and Brochothrix spp., the early communities harbored bacteria common in environmental sources and bovine microbiomes (Garcia-Lopez, et al. 1998, Holzapfel. 1998) such as Arthrobacter spp., Clostridium spp., Enterococcus spp., Janthinobacterium spp., Kocuria spp., Lactobacillus spp., Luteococcus spp., Microbacterium spp. and Pseudomonas spp. (Fig. 2; see also Table S3). The late bacterial communities dominated mainly by Carnobacterium spp. and Brochothrix spp. (Fig. 2) appear to be characteristic to this product and differ from those reported previously for high- $\mathrm{O}_{2}$ MAP beef (Ercolini, et al. 2006, Jääskeläinen, et al. 2016, Stoops, et al. 2015). From the viewpoint of meat spoilage, B. thermosphacta, Carnobacterium spp., Lactococcus spp. and Leuconostoc 
spp. are interesting, as they have been associated with unacceptable buttery or cheesy off-odors in MAP meats (Casaburi, et al. 2011, Doulgeraki, et al. 2012, Jääskeläinen, et al. 2016, Pothakos, et al. 2014, Vihavainen and Björkroth. 2007). Also in our study, sensory analysis showed that the beef product studied was susceptible to buttery spoilage type (Table S1).

In contrast to samples under a high- $\mathrm{O}_{2} \mathrm{MA}$, the communities in the samples of lot $\mathrm{C}$ were heavily (> 77\% relative abundance) dominated by Lactococcus spp., with the remaining bacteria being mainly Leuconostoc spp. and Carnobacterium spp. (Fig. 2). The relatively low $\mathrm{O}_{2}$-levels in the MA of lot $\mathrm{C}$ packages may have contributed to the distinct community profiles (see UniFrac clustering in Fig. 1) because Lactococcus spp. associated with meat spoilage are reported to be sensitive to high $\mathrm{O}_{2}$ tensions, but competent meat spoilage bacteria in an $\mathrm{MA}$ with low $\mathrm{O}_{2}$ concentrations (Nieminen, et al. 2015, Pothakos, et al. 2014,).

\subsection{Bacterial community succession pattern}

Regarding bacterial succession during 8-12 days refrigerated storage, the late communities showed a statistically significant $(p<0.05)$ increase (excluding lot $C)$ in the relative abundances of Carnobacterium spp., Brochothrix spp. and Leuconostoc spp.

(Fig. S2), and suggested a succession pattern that was reproducible across production lots. The mechanisms driving bacterial succession that occurs in cold-stored MAP meats are still poorly understood, but the MA appears to be a major force shaping the community structure. Previous works have suggested that packaging beef under a high$\mathrm{O}_{2}$ MA may select for Leuconostoc spp. (Pothakos, et al. 2014, Stoops, et al. 2015), and particularly those with a capacity for heme-dependent respiration (Jääskeläinen, et 
al. 2016, Nieminen, et al. 2015). However, the largest fractions of the late communities in this product were composed of Carnobacterium spp. and Brochothrix spp. (Fig. 2; see also Table S3). The exact factors influencing their dominance among other psychrotrophic bacteria in the late communities are not clear, but we hypothesize that their abundance in the initial meat community contributed to their competence and the overall succession pattern. It is also possible that the OTUs assigned to Leuconostoc spp. in our study represented strains that are not particularly competitive in high- $\mathrm{O}_{2}$ MAP meats. Identification of a subset of LAB colonies supported this assumption (see Fig. S3): Leuconostoc strains recovered by culturing were mainly Leuconostoc gelidum subsp. gelidum and Leuconostoc carnosum (Fig. S3) and hence, members of the genus Leuconostoc, whose growth has not been reported to be stimulated by oxygen (Rahkila, et al. 2014).

\section{Conclusions}

Our study showed that the developing spoilage bacterial communities in a high- $\mathrm{O}_{2}$ MAP beef product were similar between samples from different production lots, and that Carnobacterium spp. Brochothrix spp., Leuconostoc spp. and Lactococcus spp. were the predominant bacteria associated with product spoilage. Moreover, we showed that abundant OTUs assigned to Carnobacterium spp. Brochothrix spp., Leuconostoc spp. and Lactococcus spp. were widely shared across production lots and detected also as part of the spoilage communities. This suggests that these potential spoilage bacteria have common contamination routes or sources along the production chain. While the MA composition plays a key role in shaping the bacterial community in meat during refrigerated storage, more research is needed to identify the production conditions and 
practices prior to meat packaging that influence the abundance of potential spoilage bacteria in meat microbiomes.

\section{Acknowledgements}

We thank the quality managers of the meat processing plant for collaboration, and

Henna Niinivirta for help with the laboratory work. JH was funded by the Academy of Finland, grant number 267623. 


\section{References}

Altschul, S. F., Gish, W., Miller, W., Myers, E. W. and Lipman, D. J. 1990. Basic local alignment search tool. J. Mol. Biol. 215, 403-410.

Caporaso, J. G., Kuczynski, J., Stombaugh, J., Bittinger, K., Bushman, F. D., Costello, E. K., Fierer, N., Pena, A. G., Goodrich, J. K. and Gordon, J. I. 2010a. QIIME allows analysis of high-throughput community sequencing data. Nature methods 7, 335-336.

Caporaso, J. G., Bittinger, K., Bushman, F. D., DeSantis, T. Z., Andersen, G. L. and Knight, R. 2010b. PyNAST: a flexible tool for aligning sequences to a template alignment. Bioinformatics 26, 266-267.

Casaburi, A., Nasi, A., Ferrocino, I., Di Monaco, R., Mauriello, G., Villani, F. and Ercolini, D. 2011. Spoilage-related activity of Carnobacterium maltaromaticum strains in air-stored and vacuum-packed meat. Appl. Environ. Microbiol. 77, 7382-7393.

Chaillou, S., Chaulot-Talmon, A., Caekebeke, H., Cardinal, M., Christieans, S., Denis, C., Desmonts, M. H., Dousset, X., Feurer, C. and Hamon, E. 2015. Origin and ecological selection of core and food-specific bacterial communities associated with meat and seafood spoilage. The ISME journal 9, 1105-1118.

De Filippis, F., La Storia, A., Villani, F. and Ercolini, D. 2013. Exploring the sources of bacterial spoilers in beefsteaks by culture-independent high-throughput sequencing. PLoS One 8, e70222. 
DeSantis, T. Z., Hugenholtz, P., Larsen, N., Rojas, M., Brodie, E. L., Keller, K., Huber, T., Dalevi, D., Hu, P. and Andersen, G. L. 2006. Greengenes, a chimera-checked 16S rRNA gene database and workbench compatible with ARB. Appl. Environ. Microbiol. 72, 5069-5072.

Doulgeraki, A. I., Ercolini, D., Villani, F. and Nychas, G. E. 2012. Spoilage microbiota associated to the storage of raw meat in different conditions. Int. J. Food Microbiol. 157, 130-141.

Dušková, M., Kameník, J., Lačanin, I., Šedo, O. and Zdráhal, Z. 2016. Lactic acid bacteria in cooked hams - Sources of contamination and chances of survival in the product. Food Control 61, 1-5.

Edwards, U., Rogall, T., Blocker, H., Emde, M. and Bottger, E. C. 1989. Isolation and direct complete nucleotide determination of entire genes. Characterization of a gene coding for 16 S ribosomal RNA. Nucleic Acids Res. 17, 7843-7853.

Ercolini, D. 2013. High-throughput sequencing and metagenomics: moving forward in the culture-independent analysis of food microbial ecology. Appl. Environ. Microbiol. 79, 3148-3155.

Ercolini, D., Russo, F., Torrieri, E., Masi, P. and Villani, F. 2006. Changes in the spoilage-related microbiota of beef during refrigerated storage under different packaging conditions. Appl. Environ. Microbiol. 72, 4663-4671. 
Ercolini, D., Ferrocino, I., Nasi, A., Ndagijimana, M., Vernocchi, P., La Storia, A., Laghi, L., Mauriello, G., Guerzoni, M. E. and Villani, F. 2011. Monitoring of microbial metabolites and bacterial diversity in beef stored under different packaging conditions. Appl. Environ. Microbiol. 77, 7372-7381.

Garcia-Lopez, M. L., M. Prieto, M. and Otero, A. 1998. The physiological attributes of Gram-negative bacteria associated with spoilage of meat and meat products. In:

Davies, A. and Board, R. (Eds.), Microbiology of Meat and Poultry. Blackie Academic \& Professional, London, UK, pp. 1-34.

Holzapfel, W. 1998. The Gram-positive bacteria associated with meat and meat products. In: Davies, A. and Board, R. (Eds.), Microbiology of Meat and Poultry. Blackie Academic \& Professional, London, UK, pp. 35-84.

Hultman, J., Rahkila, R., Ali, J., Rousu, J. and Björkroth, K. J. 2015. Meat Processing Plant Microbiome and Contamination Patterns of Cold-Tolerant Bacteria Causing Food Safety and Spoilage Risks in the Manufacture of Vacuum-Packaged Cooked Sausages. Appl. Environ. Microbiol. 81, 7088-7097.

Jääskeläinen, E., Hultman, J., Parshintsev, J., Riekkola, M. and Björkroth, J. 2016. Development of spoilage bacterial community and volatile compounds in chilled beef under vacuum or high oxygen atmospheres. Int. J. Food Microbiol. 223, 25-32.

Kiermeier, A., Tamplin, M., May, D., Holds, G., Williams, M. and Dann, A. 2013. Microbial growth, communities and sensory characteristics of vacuum and modified atmosphere packaged lamb shoulders. Food Microbiol. 36, 305-315. 
Li, W. and Godzik, A. 2006. Cd-hit: a fast program for clustering and comparing large sets of protein or nucleotide sequences. Bioinformatics 22, 1658-1659.

Lozupone, C. and Knight, R. 2005. UniFrac: a new phylogenetic method for comparing microbial communities. Appl. Environ. Microbiol. 71, 8228-8235.

Nieminen, T., Nummela, M. and Björkroth, J. 2015. Packaging gas selects lactic acid bacterial communities on raw pork. J. Appl. Microbiol. 119, 1310-1316.

Nieminen, T., Vihavainen, E., Paloranta, A., Lehto, J., Paulin, L., Auvinen, P., Solismaa, M. and Björkroth, K. 2011. Characterization of psychrotrophic bacterial communities in modified atmosphere-packed meat with terminal restriction fragment length polymorphism. Int. J. Food Microbiol. 144, 360-366.

Nieminen, T., Koskinen, K., Laine, P., Hultman, J., Säde, E., Paulin, L., Paloranta, A., Johansson, P., Björkroth, J. and Auvinen, P. 2012. Comparison of microbial communities in marinated and unmarinated broiler meat by metagenomics. Int. J. Food Microbiol. 157, 142-149.

Oksanen, J., Kindt, R., Legendre, P., O'Hara, B., Simpson, G. L., Solymos, P., Stevens, M. H. H. and Wagner, H. 2008. Vegan: community ecology package. R package version. 1.8-2.

Pothakos, V., Nyambi, C., Zhang, B., Papastergiadis, A., De Meulenaer, B. and Devlieghere, F. 2014. Spoilage potential of psychrotrophic lactic acid bacteria (LAB) species: Leuconostoc gelidum subsp. gasicomitatum and Lactococcus piscium, on 
sweet bell pepper (SBP) simulation medium under different gas compositions. Int. J. Food Microbiol. 178, 120-129.

Pothakos, V., Devlieghere, F., Villani, F., Björkroth, J. and Ercolini, D. 2015. Lactic acid bacteria and their controversial role in fresh meat spoilage. Meat Sci. 109, 66-74.

Price, M. N., Dehal, P. S. and Arkin, A. P. 2010. FastTree 2-approximately maximumlikelihood trees for large alignments. Plos One 5, e9490.

R Development Core Team. 2011. R: A Language and Environment for Statistical Computing.

Rahkila, R., De Bruyne, K., Johansson, P., Vandamme, P. and Björkroth, J. 2014. Reclassification of Leuconostoc gasicomitatum as Leuconostoc gelidum subsp. gasicomitatum comb. nov., description of Leuconostoc gelidum subsp. aenigmaticum subsp. nov., designation of Leuconostoc gelidum subsp. gelidum subsp. nov. and emended description of Leuconostoc gelidum. Int. J. Syst. Evol. Microbiol. 64, 12901295.

Stellato, G., La Storia, A., De Filippis, F., Borriello, G., Villani, F. and Ercolini, D. 2016. Overlap of spoilage microbiota between meat and meat processing environment in small-scale vs large-scale retail distribution. Appl. Environ. Microbiol. In press, https://doi.org/10.1128/aem.00793-16

Stoops, J., Ruyters, S., Busschaert, P., Spaepen, R., Verreth, C., Claes, J., Lievens, B. and Van Campenhout, L. 2015. Bacterial community dynamics during cold storage of 
minced meat packaged under modified atmosphere and supplemented with different preservatives. Food Microbiol. 48, 192-199.

Vihavainen, E. J. and Björkroth, K. J. 2007. Spoilage of value-added, high-oxygen modified-atmosphere packaged raw beef steaks by Leuconostoc gasicomitatum and Leuconostoc gelidum. Int. J. Food Microbiol. 119, 340-345.

Vihavainen, E. J., Murros, A. E. and Björkroth, K. J. 2008. Leuconostoc spoilage of vacuum-packaged vegetable sausages. J. Food Prot. 71, 2312-2315.

Zhao, F., Zhou, G., Ye, K., Wang, S., Xu, X. and Li, C. 2015. Microbial changes in vacuum-packed chilled pork during storage. Meat Sci. 100, 145-149. 


\section{Figure captions}

Figure 1. Principal coordinates analysis of Weighted UniFrac values between fresh (blue), use-by date (orange) and spoiled (green) beef packages. The percentage of the variation described by the plotted PC axes is indicated. Adonis $\mathrm{R}^{2} 32.2 \%$ for early (blue) and late (green and orange) storage stages $(p<0.001)$ and $R^{2} 49.4 \%$ when lot 5 was excluded from the analysis $(p<0.001)$.

Figure 2. Relative abundance of the major taxonomic groups detected by amplicon sequencing. Only OTUs with an incidence above $2 \%$ in at least one sample are shown. OTUs classified as Actinomycetales are grouped together for clarity. See also Table S3 in supplementary material for details. 
TABLE 1. Colony counts recovered shortly after packaging ("early"), at the useby date and two days after ("spoiled") from modified atmosphere packaged beef stored at $+6^{\circ} \mathrm{C}$.

\begin{tabular}{lccc}
\hline Count & \multicolumn{3}{c}{ Mean log colony count $(\mathrm{CFU} / \mathrm{g}) \pm$ standard deviation } \\
\cline { 2 - 4 } & Early $(\mathrm{n}=6)$ & Use-by date $(\mathrm{n}=6)$ & Spoiled $(\mathrm{n}=6)$ \\
\hline Aerobic plate count & $3.98 \pm 0.64^{\mathrm{a}}$ & $7.94 \pm 0.44^{\mathrm{a}, \mathrm{b}}$ & $8.02 \pm 0.63^{\mathrm{a}}$ \\
Brochothrix spp. & $2.72 \pm 0.58^{\mathrm{b}}$ & $6.55 \pm 0.71^{\mathrm{a}, \mathrm{c}}$ & $6.19 \pm 1.66^{\mathrm{b}}$ \\
Enterobacteriaceae & $1.92 \pm 0.92^{\mathrm{a}, \mathrm{c}}$ & $5.74 \pm 0.41^{\mathrm{b}, \mathrm{d}}$ & $5.20 \pm 1.40^{\mathrm{a}, \mathrm{c}}$ \\
Lactic acid bacteria & $4.43 \pm 1.35^{\mathrm{b}, \mathrm{c}}$ & $8.39 \pm 0.69^{\mathrm{c}, \mathrm{d}}$ & $8.48 \pm 0.36^{\mathrm{b}, \mathrm{c}}$ \\
\hline a,b,c,d Mean values in the same column with the same superscripts are significantly \\
different $(\mathrm{p}<0.05)$.
\end{tabular}




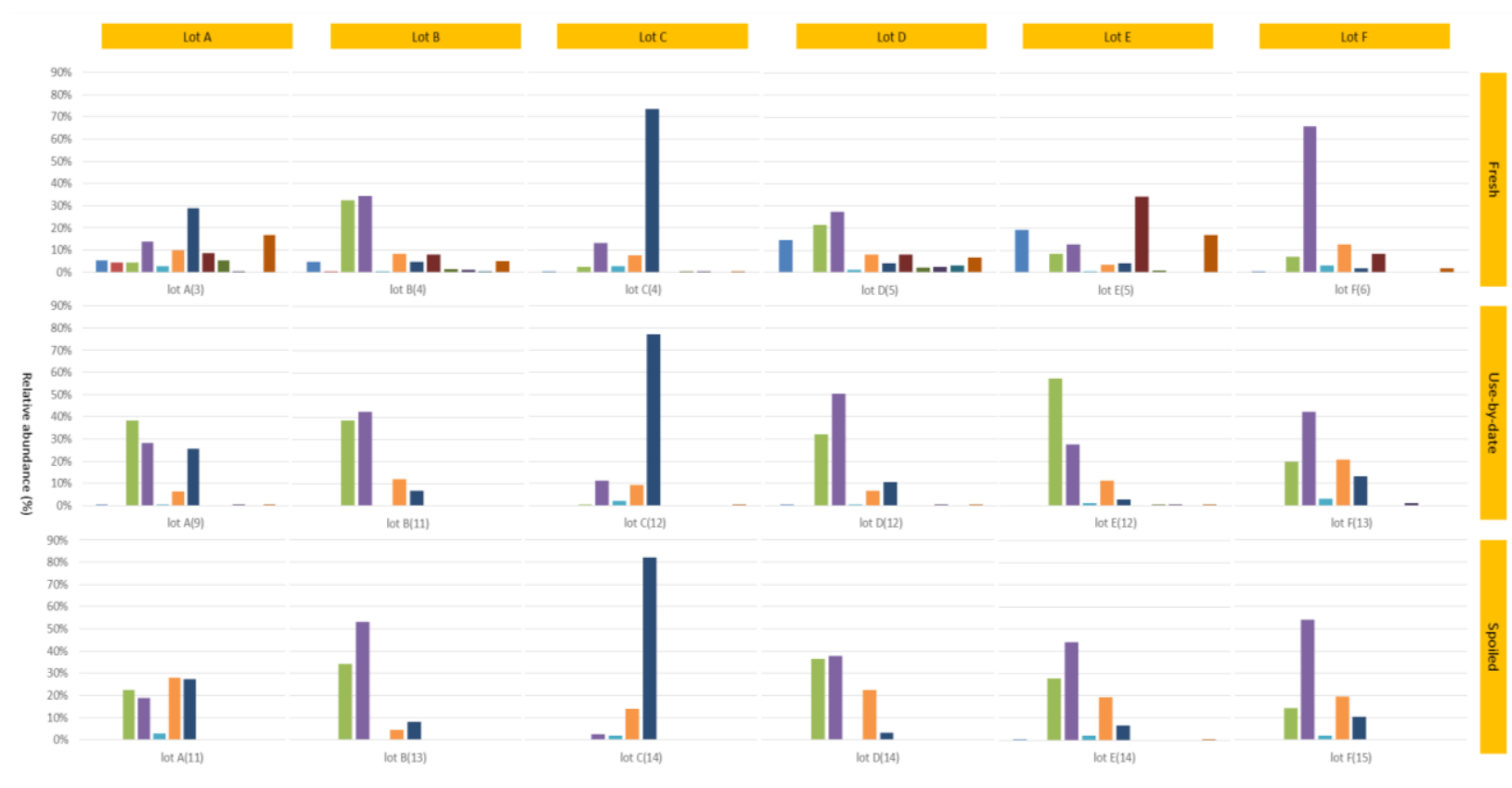

Figure 2. Säde et al. 